\title{
Indicadores ambientais aplicados ao turismo: um estudo na comunidade de Barra Grande, Cajueiro da Praia (PI)
}

\section{Environmental indicators applied to tourism: a study in the community of Barra Grande, Cajueiro da Praia (PI, Brasil)}

\author{
Anderson Fontenele Vieira, Wilza Gomes Reis Lopes, José Luis Lopes Araújo
}

RESUMO: A comunidade de Barra Grande, destino turístico localizado no município de Cajueiro da Praia, Piauí, na Área de Proteção Ambiental (APA) do Delta do Parnaíba foi objeto de investigação deste estudo. Para tanto, estabeleceu-se como objetivo identificar impactos ambientais da falta de saneamento básico em Barra Grande, considerando indicadores de sustentabilidade ambiental referentes a captação da água, tratamento de dejetos e a coleta e destinação do lixo local. A metodologia adotada constou de pesquisa bibliográfica, documental e de campo, em que o levantamento dos dados qualitativos foi realizado por meio da aplicação de entrevistas semiestruturadas com três atores da gestão pública. Constatou-se que a realidade dos serviços de saneamento básico é bastante precária e que esta potencializa impactos ambientais que influenciam diretamente no desequilíbrio do sistema ambiental. Por fim, espera-se que os dados possam contribuir para o planejamento turístico, além de construir elementos para novas abordagens de pesquisa sobre a viabilidade e adesão de segmentos turísticos sustentáveis no contexto do estado do Piauí ou de outras regiões do Brasil.

PALAVRAS-CHAVE: Destino Turístico; Delta do Parnaíba; Indicadores de Sustentabilidade Ambiental; Planejamento Turístico.

\section{ABSTRACT}

The community of Barra Grande, a tourist destination located in the municipality of Cajueiro da Praia, Piauí, in the Environmental Protection Area (EPA) of the Delta of Parnaíba was the object of investigation of this study. For this purpose, the objective was to identify environmental impacts of the lack of basic sanitation in Barra Grande, considering environmental sustainability indicators referring to water abstraction, waste treatment and the collection and disposal of local waste. The methodology adopted consisted of bibliographical, documentary and field research, in which the qualitative data was collected through the application of semi-structured interviews with three public management actors. It was verified that the reality of basic sanitation services is very precarious and that this potentiates environmental impacts that directly influence the imbalance of the environmental system. Finally, it is hoped that the data can contribute to tourism planning, as well as construct elements for new research approaches on the viability and adhesion of sustainable tourism segments in the context of the state of Piauí or other regions of Brazil.

KEYWORDS: Tourist Destination; Delta of Parnaíba; Indicators of Environmental Sustainability; Tourism Planning. 


\section{Introdução}

As questões relacionadas ao meio ambiente passaram a ser um problema global relevante a partir da década de 1970, mais precisamente em Estocolmo, no ano de 1972 e no Rio de Janeiro em 1992, onde ocorreram as Conferências Mundiais da Organização das Nações Unidas (ONU) para o Desenvolvimento (IPIRANGA; GODOY; BRUNSTEIN, 2011; CMMAD, 1991). Nesses eventos sugeriu-se o modelo internacional econômico vigente e seus processos de produção, pela responsabilidade de problemas ambientais como: poluição do ar e da água, mudanças climáticas gradativas, desmatamento de grandes áreas da flora, redução da população de grupos importantes da fauna, acúmulo de resíduos, dentre outros.

Políticas Públicas são a totalidade de ações, metas e planos, que os governos (nacionais, estaduais ou municipais) traçam para alcançar o bemestar da sociedade e o interesse público, verdadeiros instrumentos de condução do como se deve gerir de forma planejada e eficaz. No referente ao meio ambiente, o Estado deve elaborar políticas integrando princípios de preservação e conservação dos recursos naturais baseados em análises e estudos científicos, construindo um modelo com foco na sustentabilidade (BARBIERI; SILVA, 2011). Para que ocorra o desenvolvimento sustentável, os diversos membros da sociedade organizada devem se conscientizar da utilização do patrimônio natural de forma racionada mantendo-o íntegro para as gerações futuras.

É válido destacar a importância da Conferência das Nações Unidas sobre Desenvolvimento Sustentável (CNUDS), conhecida também como Rio+20, que aconteceu em 2012, no Rio de Janeiro. Esse evento teve como objetivo a renovação do compromisso político com o desenvolvimento sustentável, por meio da avaliação do progresso das lacunas na implementação das decisões adotadas pelas principais cúpulas sobre o assunto e do tratamento de temas novos e emergentes. Nos debates discutiu-se a respeito de quais seriam as melhores ações políticas (soluções) para efetivar o desenvolvimento, visto que, é difícil estabelecer um modelo aplicável que conduza a isso (MAY, 2018; SACHS, 2012).

O equilíbrio pretendido entre a atividade humana, o desenvolvimento e a proteção do ambiente exigem uma repartição de responsabilidades claramente definidas quanto ao consumo e ao comportamento face aos recursos naturais. Isso implica a integração de considerações ambientais na formulação e aplicação das políticas econômicas e setoriais, nas decisões das autoridades públicas, na operação e no desenvolvimento dos processos de produção, nos comportamentos e nas escolhas individuais (BENI, 2003).

O município de Cajueiro da Praia, localizado no estado do Piauí, latitude $02^{\circ} 55^{\prime} 40^{\prime \prime}$ e longitude $41^{\circ} 20^{\prime} 10^{\prime \prime}$ do território de desenvolvimento denominado Planície litorânea, limita-se ao norte com o Oceano Atlântico, ao sul e a oeste com o município de Luís Correia e ao leste com o estado do Ceará. Está distante $384 \mathrm{~km}$ da capital do estado, Teresina, tendo como via de acesso a PI - 301 (DER - PI, 2011; CEPRO, 2013). Esse município apresenta uma área de $271,7 \mathrm{~km}^{2}$, com uma população estimada em 7.608 pessoas e densidade demográfica de $26,36 \mathrm{hab} / \mathrm{km}^{2}$ (IBGE, 2018). 
Cajueiro da Praia faz parte do território da Área de Proteção Ambiental (APA) do Delta do Rio Parnaíba ${ }^{1}$, Unidade de Conservação (UC) de Uso sustentável, abrangendo as zonas costeiras dos territórios dos estados do Piauí, Ceará e Maranhão (MELO; MONTEIRO; BRITO, 2018; ICMBIO, 2012). Nesse contexto o turismo se desenvolve como uma das atividades econômicas local, destacando-se na principal praia denominada de Barra Grande, área objeto do estudo.

O turismo cresceu nas últimas décadas gerando mudanças, como: a) implementação de políticas públicas oriundas de todas as esferas governamentais; b) construção de empreendimentos hoteleiros, a exemplo de pousadas e hotéis; c) chegada de estrangeiros e brasileiros de outros estados interessados em empreender e residir na comunidade; d) aumento da especulação imobiliária; e, e) participação dos moradores em alguma atividade que tenha relação com o turismo, mesmo que não diretamente (VIEIRA; LOPES, 2015). Destaca-se que Barra Grande apresenta características naturais relevantes, como ventos fortes ideais para práticas esportivas radicais, a exemplo do kitesurf, área costeira e de manguezais com diversificação da flora e fauna, dentre outros fatores, que comprovam sua atratividade e necessidade de conservação.

O processo de turistificação acarreta consigo impactos transformando a realidade dos lugares onde acontece. Contudo, a maneira como esses impactos são percebidos por quem mora nas localidades receptoras (nativos) é diferente de quem vai como turista. No caso de Barra Grande, houve crescimento na instalação de equipamentos turísticos (meios de hospedagem e restaurantes), quase todos de propriedade de estrangeiros ou brasileiros não nativos. Apesar dessa situação gerar emprego e renda, movimentar a economia local e empreender mudanças socioculturais com as trocas de vivências e costumes entre os atores citados, é fato, que o nativo permanece sendo coadjuvante nesse processo.

Diante do exposto, a problemática de pesquisa baseia-se na discussão de questões levantadas, dentre outras: O turismo em Barra Grande contribui para o desenvolvimento local? Qual a realidade dos serviços de saneamento básico de abastecimento de água, tratamento de esgoto, coleta e destinação dos resíduos sólidos em Barra Grande?

Buscando atender aos questionamentos propostos, elencou-se como objetivo - identificar impactos ambientais da falta de saneamento básico em Barra Grande, considerando indicadores de sustentabilidade ambiental referentes a captação da água, ao tratamento de dejetos e a coleta e destinação do lixo local.

\section{Indicadores de desenvolvimento sustentável (IDS) aplicados ao turismo}

$\mathrm{Na}$ tentativa de se ter parâmetros capazes de direcionar as políticas, ações e projetos é que têm sido realizados estudos e pesquisas para desenvolver indicadores, que possam gerar informações sobre a realidade de regiões. Estes Indicadores de Desenvolvimento Sustentável (IDS) 
englobam as dimensões econômica, social, ambiental e institucional expressando de maneira mais coesa um conjunto de informações.

De acordo com a Comissão para o Desenvolvimento Sustentável (CDS) da Organização das Nações Unidas (ONU), encarregada em acompanhar a implantação da Agenda 21, indicadores são "[...] capazes de guiar a tomada de decisões políticas em direção ao desenvolvimento sustentável, [...] e possibilitar uma análise comparativa e específica para cada país sobre o estado atual e o progresso [...]" (CMMAD,1988, p. 85).

Com base no documento elaborado pela CDS da ONU, foram publicados, em 1996, os Indicadores de Desarollo Sostenible: Marco y Metodologías, conhecido como Livro Azul. O documento apresentou um conjunto de 134 indicadores, que foram reduzidos para 50 no ano 2000 (MALHEIROS; PHLIPPI JR, COUTINHO, 2007). O Instituto Brasileiro de Geografia e Estatística (IBGE) se baseou nesta publicação para elaborar o material IDS focalizado para o Brasil e publicado pela primeira vez em 2002, em que são utilizados 50 indicadores englobando as dimensões social, ambiental, econômica e institucional (IBGE, 2012).

Os IDS são instrumentos norteadores para elaboração das políticas públicas desenvolvimentistas, existindo abordagens metodológicas internacionais organizadas e aplicadas por diferentes instituições (IBGE, 2012). No Brasil, o IBGE publicou em 2002, 2004, 2008 e 2010, os IDS categorizados em econômicos, sociais, ambientais e institucionais. Estes, "[...] viabilizam o acesso integrado à informação já disponível sobre temas relevantes para o desenvolvimento, assim [...] apontam a necessidade de geração de novas informações" (IBGE, 2012, p. 11).

Segundo Merico (2001), a política ambiental baseada em indicadores pode levantar informações significativas quanto ao nível de sustentabilidade socioeconômica, pois a construção desses indicadores pode subsidiar a implantação de políticas associadas a melhorias dos padrões avaliados.

Assim, "al debatir el desarrollo sustentable vinculado al turismo se aprecia la necesidad de disponer de indicadores de sustentabilidad $y$ herramientas de apoyo específicas al contexto que reduzcan la subjetividad del tema (...)" (OLIVEIRA; GOMES; CÂNDIDO, 2013, p.182). Afinal de contas, os indicadores em geral, apontam uma situação presente, por meio da mensuração quantitativa ou qualitativa, e, no caso do turismo,"(...) su medición proporcionen análisis de las interferencias ocasionadas por la actividad en el desarrollo de una determinada región o destino turístico" (OLIVEIRA; GOMES; CÂNDIDO, 2013, p. 182).

No Brasil, existem estudos sobre indicadores de desenvolvimento sustentável e a correlação com o turismo, com intuito de utilizá-los como instrumentos de controle e monitoramento. Destacam-se: a elaboração de indicadores de turismo junto à comunidade do município de Bueno Brandão Minas Gerais, localizado na bacia hidrográfica do rio Mogi-Guaçu (HANAI, 2009); na comunidade de Porto de Galinhas - Pernambuco, município de Ipojuca, envolvendo os principais atores sociais da atividade turística (SANTOS, 2013); no município de Bragança - Pará (SILVA et al., 2013); no 
município de Uberaba - Minas Gerais, destino geoturístico (GODOY, 2013); e, em Bonito - Mato Grosso do Sul (TENTRIN; SANSOLO, 2006).

Nessa perspectiva, o turismo sustentável baseado em indicadores pode ser identificado como um modelo de desenvolvimento turístico mais controlado e menos impactante. Para Swarbrooke (2000, p. 6), esse tipo de turismo corresponde "as formas de turismo que satisfaçam hoje as necessidades do turista, da indústria do turismo e das comunidades locais sem comprometer a capacidade de as gerações futuras [...]". Em 2004, numa reunião na Tailândia, o Comitê de Desenvolvimento Sustentável do Turismo (CDST), órgão vinculado a Organização Mundial do Turismo (OMT), apresentou o conceito de turismo sustentável e suas inter-relações com outras esferas. Assim, as práticas de gerenciamento e manual de desenvolvimento de turismo sustentável são aplicáveis em todos os tipos de destinações. Como princípios de sustentabilidade, têm-se os aspectos ambientais, os econômicos e os socioculturais do desenvolvimento do turismo (OMT, 2005; OLIVEIRA; GOMES; CÂNDIDO, 2013).

Para a OMT (2005), os objetivos de um estudo de indicadores são a avaliação de aspectos como: proteção e pressão local, gestão de resíduos, capacidade de carga turística, entre outros. Portanto, deve ser baseada na existência e/ou geração de dados, que possibilitem o uso de metodologias com a finalidade da aplicação de indicadores para avaliação específica de determinados aspectos.

A OMT aponta os indicadores de turismo sustentável como chaves, suplementares e os de sítios específicos, sendo que os primeiros têm sido selecionados porque constituem o nível básico da informação necessária para gerir o turismo sustentável em, praticamente, qualquer destino (OMT, 2005; OLIVEIRA; GOMES; CÂNDIDO, 2013). Os suplementares, segundo a OMT (2005), são apresentados para as seguintes situações: indicadores para zonas litorâneas; montanhas; parques com gerenciamento de vida selvagem; ambientes urbanos; locais culturais; patrimônio construído; locais ecológicos singulares (em geral, destinos turísticos ligados ao ecoturismo); locais culturais (comunidades tradicionais), pequenas ilhas.

\section{Turismo de base comunitária (TBC) e o desenvolvimento local}

O turismo como toda atividade econômica, segmenta-se mercadologicamente para que possa ter melhores resultados de planejamento e gestão. Assim, o mercado turístico desenvolve-se considerando a relação entre as variáveis oferta e demanda, que precisam ser identificadas e equilibradas. No caso da oferta, por exemplo, define-se os tipos de turismo, baseado nas características estruturais, geográficas, culturais, dentre outras, que correspondem ao que o destino oferece aos turistas que o visitam (BARRETO, 2006; BRASIL, 2010).

Para demanda, a segmentação é definida pela identificação de certos grupos de consumidores, considerando fatores que determinam suas decisões, preferências e motivações (BRASIL, 2010). Destacam-se como segmentos: Turismo Social, Ecoturismo, Turismo Cultural, Turismo de 
Estudos e Intercâmbio, Turismo de Esportes, Turismo de Pesca, Turismo Náutico, Turismo de Aventura, Turismo de Sol e Praia, Turismo de Negócios e Eventos, Turismo Rural, Turismo de Saúde e Turismo de Base Comunitária (TBC) (BARRETO, 2006; BRASIL, 2010).

O TBC se destaca por ser uma alternativa ao turismo de massa, que explora os destinos de forma predatória e impactante. Este modelo relaciona a operacionalização da atividade com o bem-estar da comunidade que se apropria do turismo como uma estratégia para seu desenvolvimento socioeconômico integrado. Em outras palavras, quando se fala em comunidade é impossível não relacionar ao coletivo, integração entre pessoas convivendo em diferentes grupos sociais.

Observa-se que esse modelo turístico visa à inclusão da comunidade organizada na execução da atividade, de modo, que os atores locais (poder público e privado, e a população) articulem conjuntamente na prestação dos serviços. Nessa perspectiva, Carvalho (2010), afirma que o turismo comunitário é desenvolvido pela própria comunidade levando todos a se sentirem capazes de cooperar e organizar as estratégias para o setor. Desenvolvendo a gestão participativa, envolvendo os atores sociais nas atividades no local, de forma direta ou indireta. Tendo sempre em vista a melhoria da comunidade, levando em conta os desejos e as necessidades das pessoas, a cultura local e a valorização do patrimônio natural e cultural (SAMPAIO; CORIOLANO, 2009).

O TBC tem o desafio de minimizar as diferenças sociais e econômicas entre turistas e nativos, além de aproximar os primeiros das vivências e costumes locais, criando uma conexão equilibrada, pois "se considera que el turismo de base comunitária surge como alternativa para otra forma de desarrollo caracterizada por relaciones más armoniosas, equilibradas $y$ eficientes (...), permitiendo (...) inserción para las comunidades desfavorecidas" (SILVA et al., 2014, p. 790).

Diante disso, ressalta-se que o turismo, por ser uma atividade que depende, sobretudo, da relação entre as iniciativas pública e privada, necessita da participação dos gestores e da população local interessada em desempenhar o potencial turístico existente em uma região. Sendo que, para organizar a comunidade para o turismo é necessário estabelecer uma aliança entre interesses econômicos locais e não locais, objetivando atribuir uma relevante importância na valorização das questões culturais e ambientais, que são fatores essenciais para a motivação do turista em conhecer um determinado produto turístico (MIELKE, 2009; SILVA et al., 2014).

Ao falar em turismo de base comunitária é importante abordar sobre a representatividade dos Arranjos Produtivos Locais (APL's) na efetiva prática desse segmento do turismo. Haja visto que os APL's têm como um de seus objetivos básicos a minimização dos riscos econômicos e a valorização da autogestão, dando autonomia à comunidade no controle no desenvolvimento da atividade turística. Para Sampaio e Coriolano (2009), os arranjos produtivos devem concentrar no mesmo território empresas de pequeno 
porte, de base familiar, baixa competência técnica, comercial e gerencial, produzindo atividades terciárias para a cadeia produtiva do turismo.

Nos discursos sobre turismo comunitário é comum que projetos de turismo ligados às comunidades sejam automaticamente qualificados como comunitários, mesmo não tendo as características apresentadas. Desse modo, "[...] os princípios do enfoque de Turismo Comunitário centram-se na preservação, valorização e indução de tradições e relações sociais solidárias, na geração de trabalho e renda com base na produção associativista, [...]" (ARAÚJO; GELBCKE, 2008, p. 367).

Entretanto, alguns fatores têm contribuído negativamente para que um ambiente propício ao desenvolvimento turístico de base comunitária ocorra. Em primeiro lugar, deve-se ter em mente que a atividade turística é complexa por essência. Pois, "[...] agrupa vários elementos denominados atores sociais, que em um primeiro momento pertencem a segmentos diferentes da economia local, mas que [...] são complementares (MIELKE, 2009, p. 21)".

No Brasil existem, efetivamente, projetos de turismo comunitário que apresentam resultados significativos, reafirmando sobre os impactos positivos desse para as comunidades. Têm-se como alguns exemplos: a Prainha do Canto Verde no município de Beberibe (Ceará) e a Vila do Aventureiro (Ilha Grande), no município de Angra dos Reis (Rio de Janeiro), localidades essencialmente pesqueiras e com práticas agrícolas de subsistência, que perceberam no turismo uma nova alternativa para 0 desenvolvimento local (MENDONÇA; MORAES, 2016); e, no município de Morretes (Paraná), sudoeste da Microbacia do Rio Sagrado, composta pelas comunidades rurais de Rio Sagrado de Cima, Canhembora, Brejumirim e Candonga, estas representam uma experiência de TBC consolidado (SAMPAIO; ZAMIGNAN, 2012).

No vizinho Estado do Ceará existe a Rede Tucum, articulação de grupos organizados em treze comunidades do litoral cearense que desenvolvem iniciativas de turismo comunitário. A Rede, formada por representantes de populações de comunidades indígenas, pesqueiras e de agricultores, oferece serviços turísticos de hospedagem, alimentação, trilhas ecológicas e passeios ao mar. Tem o intuito de promover a interação entre sociedade e natureza valorizando as culturas e os territórios, integrando economicamente o turismo às atividades tradicionais (DUARTE, 2013).

Criada em 2001, a Rede Tucum reúne hoje treze comunidades litorâneas em diferentes municípios. Atualmente, compõe a rede: Tatajuba (Camocim), Curral Velho (Acaraú), Caetanos de Cima (Amontada), Flecheiras (Trairí), Etnia Tapeba (Caucaia), Etnia Índigena JenipapoKanindé (Aquiraz), Batoque (Aquiraz), Prainha do Canto Verde (Beberibe), Assentamento Coqueirinho (Fortim), Ponta Grossa (Icapuí), Tremembé (Icapuí), Centro de Formação Frei Humberto (MST-Fortaleza), Associação Mulheres em Movimento (Conjunto Palmeiras, Fortaleza) (DUARTE, 2013).

Em virtude do exposto, percebe-se que as experiências de TBC que têm tido êxito, acontecem em comunidades de pequeno porte, em que todos 
participam de forma colaborativa. Nesse contexto, os moradores locais são os atores responsáveis pelas mais diferentes atividades, que em conjunto, operacionalizam o turismo e seu desenvolvimento. Acredita-se que, a presença de empresários com grande poder de investimento e políticas focalizadas num suporte a esse público, enfraqueça a ideia chave desse segmento, que é do protagonismo da comunidade.

\section{Metodologia}

\section{Caracterização da pesquisa}

A presente pesquisa é de abordagem qualitativa e natureza aplicada, quanto aos objetivos se caracteriza como pesquisa exploratória, descritiva e explicativa. Quanto aos procedimentos foram feitas pesquisas bibliográfica, documental e de campo tendo como bases teóricas (TRIVIÑOS, 1987; GOLDENBERG, 1997; MINAYO, 2001; FONSECA, 2002; GIL, 2007). A escolha dos indicadores se deu com base na publicação - Indicadores de Sustentabilidade do IBGE - 2012. Esse estudo tem como orientação as recomendações da Comissão para o Desenvolvimento Sustentável (CDS) da ONU, com adaptações à realidade brasileira. O IBGE publicou a primeira edição em 2002, e deu continuidade a esta, nos anos de 2004, 2008, 2010, e, por fim, no ano de 2012 (IBGE, 2012).

Destaca-se que o estudo contempla quatro dimensões da sustentabilidade, sendo respectivamente: ambiental, social, econômica e institucional, em que cada uma delas apresenta indicadores específicos (IBGE, 2012). A dimensão ambiental relaciona objetivos de preservação e conservação do meio ambiente, essenciais para a qualidade de vida das gerações atuais e futuras. Nessa pesquisa foi selecionada a dimensão ambiental, organizada nos temas: atmosfera; terra; água doce; oceanos, mares e áreas costeiras; biodiversidade e saneamento, sendo este, o único utilizado para coletar os dados (IBGE, 2012).

Optou-se por trabalhar com o tema saneamento, que reúne os indicadores relacionados ao abastecimento de água, esgotamento sanitário, coleta e destinação final de lixo, pois igualmente expressam pressões sobre os recursos naturais, ações da política ambiental e influência na saúde da população (IBGE, 2012). Além do mais, esse tema é um bom exemplo da inter-relação das referidas dimensões, quando se toma como paradigma o desenvolvimento sustentável, fato que legitima a proposta interdisciplinar da pesquisa realizada em Barra Grande.

O levantamento bibliográfico foi feito durante toda a elaboração e escrita do trabalho, primariamente em livros que tratam das temáticas: turismo e meio ambiente, políticas públicas, desenvolvimento sustentável e indicadores de sustentabilidade. Depois acessando bancos de dados SciELO, Latindex, Periódicos Capes, Biblioteca digital de teses e dissertações e Google acadêmico - em busca de artigos, teses e dissertações correlatas ao tema. Foram utilizados documentos de políticas públicas relacionadas a questão ambiental para sistematizar informações à respeito dos temas base. 


\section{Sujeitos da pesquisa}

Este estudo foi aprovado pelo Comitê de Ética em Pesquisa (CEP) da Universidade Federal do Piauí (UFPI), com registro 46094215.3.0000.5214, atendendo ao que pressupõe a Resolução 466/2012 da Comissão Nacional de Ética e Pesquisa do Ministério da Saúde. O levantamento dos dados qualitativos foi realizado por meio da aplicação de entrevistas semiestruturadas e específicas com três sujeitos selecionados por serem envolvidos com a gestão pública local e conhecerem sobre o saneamento básico, sendo: o Secretário municipal de Turismo e Meio Ambiente de Cajueiro da Praia, um Vereador da Câmara municipal e um técnico da empresa pública AGESPISA. Ressalta-se que a pesquisa foi aplicada entre os meses de janeiro a fevereiro de 2016, e que todos concordaram em assinar o Termo de Consentimento Livre e Esclarecido (TCLE). A entrevista tinha a intenção de compreender por meio da percepção dos sujeitos como era feita a captação da água, tratamento de dejetos, coleta e destinação final do lixo municipal.

\section{Análise dos dados}

O (Quadro 1) apresenta os parâmetros utilizados pelo IBGE, em que os indicadores abordados estão na primeira coluna; na segunda coluna, a qualificação para o que seria considerado como adequado e a terceira coluna apresenta o que, para o estudo, é visto como inadequado (IBGE, 2012). No referente a análise dos dados utilizou-se da técnica de análise do conteúdo, de modo a relacionar as condições de saneamento achadas pelo pesquisador em campo por meio da observação direta com as percepções dos entrevistados à respeito dos indicadores. A partir desse comparativo, constatamos como eram as condições de saneamento básico em Barra Grande e quais os impactos ambientais consequentes da falta desse. Destaca-se que na seção das análises os sujeitos da pesquisa são nomeados pelas iniciais dos nomes e função que exercem.

Quadro 1: Parâmetros dos Indicadores de Saneamento.

Table 1: Parameters of Sanitation Indicators.

\begin{tabular}{|l|l|l|}
\hline \multirow{2}{*}{ INDICADORES } & \multicolumn{1}{c|}{ QUALIDADE DA OFERTA } \\
\cline { 2 - 3 } $\begin{array}{l}\text { Abastecimento de } \\
\text { água. }\end{array}$ & $\begin{array}{l}\text { ADEQUADO } \\
\text { gede de abastecimento }\end{array}$ & $\begin{array}{l}\text { Abastecimento domiciliar (poço, } \\
\text { nascente, água de chuva e etc.). }\end{array}$ \\
\hline $\begin{array}{l}\text { Esgotamento } \\
\text { sanitário. }\end{array}$ & $\begin{array}{l}\text { Rede coletora ou fossa } \\
\text { séptica; } \\
\text { Tratamento em ETE. }\end{array}$ & $\begin{array}{l}\text { Sem rede ou fossa séptica; } \\
\text { despejo sem tratamento } \\
\text { adequado. }\end{array}$ \\
\hline $\begin{array}{l}\text { Coleta e destinação } \\
\text { final do lixo }\end{array}$ & $\begin{array}{l}\text { Coleta de lixo doméstico; } \\
\text { aterros sanitários ou } \\
\text { estações de (triagem, } \\
\text { reciclagem e compostagem). }\end{array}$ & $\begin{array}{l}\text { Sem coleta de lixo doméstico; } \\
\text { vazadouros a céu aberto ou } \\
\text { áreas alagadas e queima a céu } \\
\text { aberto. }\end{array}$ \\
\hline
\end{tabular}

Fonte: IBGE (2012) adaptado pelos autores, 2015.

Source: IBGE (2012) adapted by the authors, 2015. 


\section{Resultados}

\section{A comunidade de Barra Grande e o desenvolvimento do turismo}

Barra Grande é uma comunidade litorânea localizada na região norte do estado do Piaú́, Brasil, latitude sul $-2^{\circ} 54^{\prime} 48.7^{\prime \prime}$ e longitude oeste $41^{\circ} 24^{\prime} 57.8^{\prime \prime}$ (IBGE 2010), mais precisamente no município de Cajueiro da Praia, com área urbana de 78 hectares e uma faixa de praia com $4 \mathrm{~km}$ de extensão, onde vivem cerca de 1.500 habitantes (MACÊDO; RAMOS, 2012). $\mathrm{Na}$ figura 1 visualiza-se um recorte de mapa do traçado rodoviário da porção norte do estado do Piauí, com destaque para os cinco municípios do Polo Costa do Delta ${ }^{2}$ - Parnaíba, Luís Correia, Cajueiro da Praia, Illa Grande e Buriti dos Lopes, bem como as rodovias estadual e federais (PI - 116, BR 343 e BR - 402), que dão acesso à área objeto de estudo.

O turismo passou a ser uma das principais atividades desenvolvidas na região, proporcionando modificações na comunidade, como: ampliação da estrutura de receptivo com mais equipamentos turísticos a exemplo de hotéis, pousadas, restaurantes e bares, crescente chegada de turistas nacionais e internacionais efetivando residência na localidade, formação de novos postos de trabalho para os residentes e atuação governamental por meio de políticas em âmbito nacional, estadual e municipal de desenvolvimento turístico (COSTA, 2006; MACÊDO; RAMOS, 2012; VIEIRA; LOPES, 2015; CUNHA; SILVA, 2018).

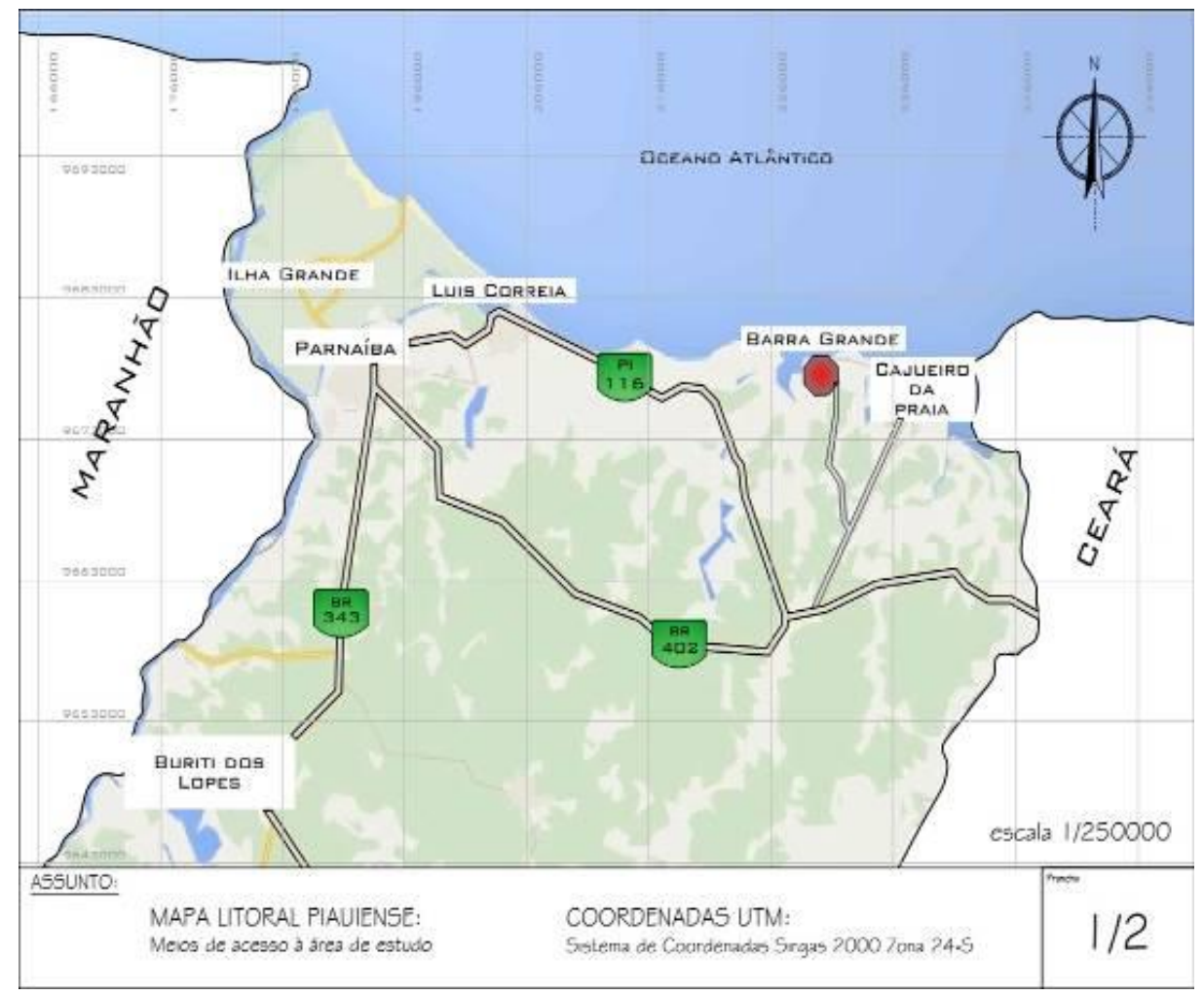

Figura 1: Recorte de mapa do traçado rodoviário da porção norte do Piauí, com destaque para os cinco municípios do Polo Costa do Delta.

Figure 1: Mapping of the road map of the northern portion of Piauí, highlighting the five municipalities of the Costa do Delta Polo.

Fonte: Google Maps (2016) adaptado por Ozian Gomes Feijó, 2016.

Source: Google Maps (2016) adapted by Ozian Gomes Feijó, 2016. 
Com base em visitas feitas a Barra Grande, em 2018, e por meio de buscas em um site local ${ }^{3}$ sobre a praia, seus atrativos e serviços turísticos, levantamos um quantitativo de mais de 40 pousadas, 25 bares/restaurantes e 12 lojas com serviços que vão desde mercantis, farmácias e frutarias, a locais que vendem equipamentos para a prática do kitesurf, confirmando o crescimento do receptivo local. Constatou-se também que a prefeitura de Cajueiro da Praia não dispõe de dados que confirmem esses números e no site do Cadastur (Cadastro de Prestadores de Serviços Turísticos), responsável por fornecer informações aos turistas sobre o número e quem são os prestadores regulamentados ao Ministério do Turismos (MTUR), o quantitativo de empresas cadastradas é bem menor que o encontrado atualmente. Com isso concluímos que a falta de dados sistematizados sobre a atividade turística local reforça que a gestão pública reproduz o mesmo posicionamento de outros destinos ainda não consolidados, tratando 0 turismo de forma amadora e sem controle do crescimento da atividade e de seus consequentes impactos.

Reproduzindo o que acontece em todo o estado do Piauí, não existem estudos recentes sobre a demanda de turistas, mas empiricamente podemos caracterizar o turismo em Barra Grande como doméstico, principalmente, com a presença de turistas do próprio estado e dos vizinhos Maranhão e Ceará, além dos vindos da região Sudeste. Existe uma presença muito significativa de estrangeiros vindos do continente Europeu para praticar esportes à vela. O turismo local é sazonal acontecendo nos meses de janeiro, fevereiro, junho, julho, agosto, setembro e dezembro, períodos de férias escolares e de trabalhadores em geral; além das férias dos europeus e em que os ventos são mais propícios para os esportes.

Quanto as relações de trabalho no âmbito da comunidade percebe-se uma dinâmica comum e consequente do turismo em locais de pequeno porte, como a área objeto de estudo. Os moradores nativos conseguem inserção no mercado de trabalho, geralmente, em funções relacionadas à operacionalização dos serviços, como: recepcionistas, camareiras, cozinheiro(a)s e serviços gerais, por exemplo. Durante a aplicação da pesquisa constatamos isso, e observamos também, que apenas uma das pousadas era de propriedade de um nativo, corroborando que o turismo enquanto atividade econômica de viés capitalista reproduz relações em que o nativo fica a margem dos benefícios da atividade, juntamente com a precarização do trabalho, comum na prestação de serviços (CUNHA et al., 2016).

Barra Grande tem se tornado um produto promocional do turismo no estado do Piauí, apesar da pouca atuação dos órgãos estaduais na elaboração e execução de estratégias de promoção e marketing turísticos. A praia tem sido amplamente divulgada por blogs e sites de viagens nacionais e internacionais, como: Booking, Tripadvisor, Viaje na viagem, Guia viajar melhor e Viagem e turismo, dentre outros, responsáveis por abordar temas sobre o setor e divulgar destinos (SILVA et al., 2016).

A comunidade tem seu núcleo original estruturado ao longo do acesso rodoviário à praia e apresenta potencial para os segmentos do ecoturismo, 
turismo de esportes e turismo de base comunitária. Contudo, o que se percebeu é a predominância do turismo de esportes com foco para o kitesurf, prática "quase exclusiva" de quem possui recursos para manter e investir no esporte, considerado caro e excludente. Ainda como consequência, existem conflitos entre praticantes, pescadores e órgãos fiscalizadores ambientais, Instituto Chico Mendes de Conservação da Biodiversidade (ICMBIO) e Secretaria Estadual de Meio Ambiente e Recursos Hídricos (SEMAR). Tivemos a oportunidade de participar, em 2018, de um evento local com a presença desses atores sociais que tinha como prioridade regular a delimitação de áreas para a pesca e o kitesurf, na busca pela minimização dos riscos de acidentes e influência na pescaria (FREITAS et al., 2012).

Verificou-se também um forte apelo para o que intitularemos de "ecoturismo capitalista", pois apesar dos empreendimentos realizarem práticas sustentáveis, contratarem nativos e estimularem o consumo dos recursos naturais racionalizada, há uma supervalorização na cobrança dos serviços prestados. Corroborando que o turismo desenvolvido em Barra Grande tem replicado o que acontece em outros destinos turísticos de massa, um turismo excludente, destinado para àqueles que podem se proporcionar determinados serviços. Dessa forma, apesar do local ter características que possibilitariam o TBC, dificilmente como a atividade acontece hoje se conseguiria criar uma atmosfera comunitária que envolvesse, principalmente, a participação dos nativos.

Historicamente falando Barra Grande é frequentada para fins de veraneio, desde a década de 1980, por piauienses provenientes, principalmente, de Teresina e Parnaíba, que possuíam ou alugavam casas para passar a temporada de férias e fins de semana prolongados e de residentes de municípios do estado vizinho, Ceará (MACÊDO; RAMOS, 2012; VIEIRA; LOPES, 2015). A partir do ano de 2005, com a exploração do kitesurf, Barra Grande inicia seu reconhecimento como destino turístico estadual, sendo visitada por pessoas vindas de São Paulo e Rio de Janeiro (MACÊDO; RAMOS, 2012). Contudo, a pesca, a agricultura de subsistência e as práticas comerciais em pequena escala são atividades econômicas mais comuns e tradicionais entre os nativos.

Durante as etapas da pesquisa de campo foi perceptível, que o turismo se apresenta como uma atividade característica na região que contempla Cajueiro da Praia. Essa atividade foi capaz de motivar mudanças no contexto local, que outras práticas econômicas não geraram. Um exemplo claro disso, é o crescente número de pousadas funcionando e em construção, superando o quantitativo de municípios, como: Parnaíba e Luís Correia, detentoras de infraestrutura básica e de apoio melhores, além de terem atrativos turísticos potencializadores de fluxo de visitantes.

Além da atratividade de Barra Grande, motivada por meio do turismo de aventura com o kitesurf e de suas belezas naturais, que corroboram para sua potencialidade turística nos segmentos de ecoturismo e de sol e mar, destacam-se os hábitos e costumes dos moradores locais como aspectos a serem explorados. Afinal de contas, as questões culturais têm sido um 
diferencial, para as localidades operarem numa perspectiva de desenvolvimento da atividade com foco para sustentabilidade e menos impactos negativos aos espaços naturais.

Em Cajueiro da Praia, por exemplo, as práticas religiosas e festivas são bastante tradicionais, sendo as principais: a Regata de Canoas (anualmente), a Folia de Reis (Janeiro), os Festejos de São Pedro (Junho) e os Festejos de Nossa Senhora de Fátima (Maio) (MACÊDO; RAMOS, 2012). Os Festejos juninos de São Pedro, padroeiro dos pescadores é o mais valorizado, comunitariamente, devido à população ativa de trabalhadores ser composta por homens pescadores. Durante uma das etapas da pesquisa de campo, estavam acontecendo os festejos juninos na igreja de Barra Grande.

A gestão pública do turismo dispõe de uma Secretaria de Turismo e Meio Ambiente, criada em 2009, que não possui sede própria e tem uma sala compartilhada no prédio da Prefeitura municipal. Segundo M. C. (2016), Secretário de Turismo, existe interesse por parte da gestora local em investir no setor, e que, há monitoramento na qualidade dos serviços ofertados aos turistas, que vêm a Cajueiro da Praia e Barra Grande. Existem também, instituições governamentais e não governamentais, que compartilham a gestão turística, sendo: SEBRAE, IBAMA, Instituto Chico Mendes, Banco do Nordeste, Aliança Mandu e Associação de Condutores Barratur (COSTA, 2006, MACÊDO; RAMOS, 2012).

\section{Indicadores ambientais de saneamento em Barra Grande e sua influência no turismo}

Em relação à infraestrutura urbana, Barra Grande conta com rede pública de abastecimento de água com capacidade para atender 786 domicílios. De acordo com o técnico da Prefeitura de Cajueiro da Praia, L. D. (2016), essa água é distribuída pela empresa pública Águas e Esgotos do Piauí S/A (AGESPISA), desde 2001, por meio de redes de distribuição convencionais, com reservatório capaz de armazenar $200 \mathrm{~m}^{3}$ ou 200.000 (duzentos mil litros). A captação da água é realizada por poços artesianos, que bombeiam diretamente na adutora e sem tratamento conforme os protocolos recomendados. O técnico afirmou que o tratamento consiste, apenas, na cloração e desinfecção, atestando a baixa qualidade da água ofertada. Para Souza et al. (2014, p. 30): "a qualidade da água é um conceito relativo que depende diretamente do uso a que se destina seja este para balneabilidade, consumo humano, irrigação, transporte e manutenção da vida aquática". Ainda na perspectiva dos autores, "para cada um dos usos existe um padrão de qualidade especificado pela legislação" (SOUZA et al., 2014, p. 30).

Segundo M. C. (2016), Secretário de Turismo e Meio Ambiente de Cajueiro da Praia, a Prefeitura solicita reforço na distribuição, principalmente, nos períodos de maior fluxo, pois o abastecimento gera insatisfação na comunidade. É comum, por exemplo, que os proprietários dos equipamentos de hospedagem comprem água de carros pipas para atender a demanda de clientes, além da venda de água mineral ser um dos negócios mais 
lucrativos para comerciantes locais, por conta da baixa qualidade da água fornecida pela AGESPISA para o consumo humano. Nesse sentido, Souza et al. (2014, p. 30), apontam que "o crescimento demográfico e o desenvolvimento social e econômico aumentam a demanda por água e provocam alterações de ordem física, química e biológica nos ecossistemas aquáticos".

Durante a coleta de dados foi relatado por um usuário proprietário de pousada, que foram feitos estudos sobre a qualidade da água disponibilizada, tendo como resultado a presença de ferrugem e coliformes fecais. "Um dos aspectos (...) da qualidade da água é que ela esteja livre de impurezas, entre elas, a contaminação fecal que representa grande risco à saúde humana por conter patógenos" (SOUZA et al., 2014, p. 37). De acordo com a Resolução do Conselho Nacional do Meio Ambiente (CONAMA) oㅜ 357, coliformes fecais são definidos como bactérias gram-negativas e em forma de bacilos, presentes em fezes humanas e de outros animais homeotérmicos (BRASIL, 2005).

Com isso constatamos que o indicador abastecimento de água se encontra em desacordo com o que estabelece o IBGE, devido a rede geral ser insuficiente, além de ainda ser comum o abastecimento domiciliar por meio de poços. Para (SOARES; EMMENDOERFER; MONTEIRO, 2013), a integração dos atores públicos dialogando com a iniciativa privada é fundamental no planejamento da atividade. No caso de Barra Grande, a relação da prefeitura de Cajueiro da Praia e AGESPISA com os empreendedores locais deve ser na tentativa de buscar soluções para que a problemática da água não influencie diretamente no turismo.

No âmbito da pesquisa de campo, uma das questões que gerou maior preocupação foram os resíduos sólidos produzidos e seu destino final. Ficou claro que não há tratamento adequado para o lixo coletado nas pousadas, domicílios e comércios, pois este é despejado a céu aberto, em um lixão inapropriado na entrada de Barra Grande e próxima a uma área de mangue. Segundo J. C. (2016), vereador do Município de Cajueiro da Praia, esse "lixão" é de propriedade privada e sua área está sendo cercada. O parlamentar afirmou ainda, que existe também um outro lixão no município sede, onde os resíduos sólidos são colocados em valas e depois cobertos com o mesmo material dessas valas.

Sobre a destinação pública dos resíduos sólidos rejeitados, de fato, continuam existindo no Brasil basicamente três tipos: aterros sanitários, aterros controlados e lixões (vazadouros) (SPERB; TELLES, 2014). Segundo o Instituto de Pesquisa Econômica Aplicada (IPEA), foi verificado no ano de 2014 que do total de 5.564 municípios brasileiros, 2.507 ainda destinam os resíduos sólidos a lixões (45\%), que são áreas que se apresentam sem nenhum controle ambiental e a céu aberto, sendo que 0 município de Cajueiro da Praia ainda faz parte desse grupo (IPEA, 2014).

O Secretário de Turismo e Meio Ambiente de Cajueiro da Praia disse que há apoio da gestão pública e que são feitas campanhas de conscientização ambiental nas escolas municipais, além do serviço de limpeza constante, que evita focos de lixo acumulado. Porém, durante as 
visitas in loco foram comprovados pontos de acúmulo de resíduos, além de ter sido esse um dos pontos negativo mais citado pelos sujeitos da pesquisa. $\mathrm{Na}$ rua em que ficam a maioria das pousadas e na praia, próximo aos bares, foi possível observar latas de lixo padronizadas com o slogan da prefeitura. Sendo essa a única ação perceptível à respeito da coleta do lixo no local enquanto o estudo foi aplicado.

Complementarmente, segundo a Política Nacional de Resíduos Sólidos (PNRS), de uma forma geral, deve ser observada na gestão e gerenciamento de resíduos sólidos, a seguinte ordem de prioridades: não geração, redução, reutilização, reciclagem, tratamento dos resíduos sólidos e disposição final ambientalmente adequada dos rejeitos (PNRS, 2010). Porém se considerarmos a situação encontrada com as recomendações da política nacional vemos muitas divergências, aliadas à realização de ações isoladas das quais não se sabe a continuidade.

Somado a isso destaca-se a precariedade do serviço de saneamento básico, a falta de rede coletora de esgoto sanitário no município de Cajueiro da Praia, utilizando-se de fossas negras/sumidouros, ainda existentes em muitas áreas. De acordo com J. C. (2016), Cajueiro da Praia está incluído nos cem municípios do estado do Piauí contemplados e selecionados para participarem da capacitação e elaboração dos Planos Municipais de Saneamento Básico (PMSB), Lei de Saneamento Básico 11.445/2007, e portaria 141/2016, em concordância com o diário Oficial da União. Ressaltase que, esses municípios tinham até, 31 de dezembro de 2016, para apresentarem seus planos. Contudo, o que verificamos é que o prazo estabelecido não foi cumprido e em se tratando dos indicadores - coleta e destinação final do lixo e esgotamento sanitário - Barra Grande não está de acordo com o que o IBGE estabelece como adequado, em relação ao primeiro devido o lixo ser despejado em um vazadouro a céu aberto, quanto ao segundo, pois não existe rede coletora ou presença de fossas sépticas.

Conclui-se que, a solução desses problemas de infraestrutura é condição necessária para melhoria do bem-estar da população e de quem visita a região, pois contribuem como vetores de doenças e redução na qualidade de vida da população residente. Do ponto de vista do turismo, geram depreciação na condição dos atrativos e do destino como um todo, comprometendo a percepção positiva do visitante em relação ao local visitado.

Dentre os problemas ambientais diretamente associados ao turismo pode-se citar, ainda, o acúmulo de lixo em pontos de visitação, o impacto causado por embarcações (poluição com óleo, por exemplo) e procedimentos inadequados, tais como a falta de armazenamento e tratamento adequado para os resíduos gerados nos passeios e alterações na paisagem original por meio da ocupação da faixa de praia por casas de veranistas (COSTA, 2006; MACÊDO; RAMOS, 2012; VIEIRA; LOPES, 2015).

Contudo, pelo que foi observado durante a pesquisa de campo, é fato, que Barra Grande tem um déficit muito grande, quanto à infraestrutura básica nos três itens estudados pela pesquisa. Sabe-se que isso, não é uma 
problemática que reflete o contexto somente dessa comunidade, mas sim, um cenário em nível estadual e nacional. Acredita-se que a chegada de pessoas vindas de outros lugares do Brasil e de outros países contribui para estimular mudanças comportamentais nos nativos; no sentindo de sugerir ações simples e práticas capazes de empreender melhorias nos problemas estruturais relatados.

\section{Considerações Finais}

O turismo em Barra Grande configura-se como uma das principais atividades para o desenvolvimento socioeconômico, potencializando a geração de emprego e renda, além de trocas socioculturais entre nativos e turistas. Destaca-se que muitos jovens locais conseguiram se inserir como funcionários dos meios de hospedagem; os pescadores passaram a fornecer seus pescados aos restaurantes e pousadas; e o comércio varejista, também ativou a comercialização de mercadorias, movimentando a economia local.

Constatou-se que a realidade dos serviços de infraestrutura básica, referentes à água, tratamento de dejetos, coleta e destinação do lixo em Barra Grande é bastante precária. O fato é que a ausência de saneamento básico por si só é um problema de dimensão preocupante. Nessa perspectiva, pode-se citar como consequências ambientais negativas: a poluição do ar, contaminação do solo, das águas superficiais e subterrâneas pelo lixão a céu aberto existente, e ainda, pelo tratamento dos dejetos por meio de fossas rudimentares, única modalidade utilizada na área.

Os impactos ambientais causados pela falta se saneamento somados a outros influenciam diretamente no desequilíbrio do sistema ambiental da região estudada, pois não estão de acordo com o estudo de IDS do IBGE. Os dejetos gerados pelas pousadas colaboram para diminuição da qualidade da água do lençol freático, fonte para os poços artesianos largamente utilizados, além da que é ofertada pela AGESPISA. No caso do lixo, com o aumento da produção nos períodos de maior fluxo de turistas e a ausência de local para tratamento adequado, há um impacto direto nas áreas de mangue, tendo em vista que o lixão da comunidade se situa nos arredores.

O planejamento do turismo e das políticas que o direcionam, considerando o viés da sustentabilidade é uma alternativa constantemente apresentada em estudos de destinos nacionais com características semelhantes à Barra Grande. Porém, não se percebe nessas pesquisas, propostas de metodologias baseadas em indicadores objetivos, que possam qualificar efetivamente os efeitos negativos ao meio ambiente, e consequentemente, levantar informações significativas para elaboração de medidas na mitigação desses impactos. Na comunidade estudada, por exemplo, essas políticas poderiam estimular a adoção de medidas ambientais efetivas.

Barra Grande teve sua promoção do desenvolvimento turístico resultante, entre outros motivos, de uma Política Nacional de Turismo, que objetivou a descentralização da gestão do turismo. Atualmente, o município 
de Cajueiro da Praia, onde a comunidade está localizada, faz parte do Programa de Regionalização do Turismo Roteiros do Brasil, que é um programa federal. Em âmbito estadual, identificou-se o PRODETUR/NE projeto, que contempla a região, mas faz parte de uma articulação federal. Do ponto de vista local, destaca-se o Plano Estratégico do Turismo de Barra Grande (2008-2013) elaborado pelo SEBRAE/PI e Secretaria Municipal de Turismo.

Espera-se que os dados levantados possam contribuir na condução do planejamento e gestão das políticas de turismo e meio ambiente, além de construir parâmetros para subsidiar discussões e novas abordagens de pesquisa, que contemplem a viabilidade e adesão de modelos de turismo sustentável, como o ecoturismo. Destaca-se que no próprio Plano de Manejo da APA do Delta do Parnaíba, o ecoturismo é considerado uma das atividades específicas a ser desempenhadas na conservação do ecossistema.

\section{Notas:}

1 Considerado o terceiro maior do mundo e o único encontrado no Continente Americano a desaguar diretamente no oceano, possui uma ampla área de cobertura com cerca de $2.750 \mathrm{Km}^{2}$, e é caracterizado como um complexo mosaico de ecossistemas entrecortados por baías e estuários. Situado entre os Estados do Piauí e Maranhão, caracteriza-se como uma região flúvio-marinha bastante dinâmica formada pela tensão ecológica entre as formações de Cerrado, Caatinga e Sistemas marinhos. Devido à sua alta produtividade primária é considerado como um santuário reprodutivo para inúmeras espécies migratórias (GUZZY, 2012).

${ }^{2}$ Atualmente, o estado do Piauí está dividido em sete polos turísticos, sendo: Polo Aventura e Mistério, Polo Costa do Delta, Polo das Aguas, Polo das Nascentes, Polo das Origens, Polo Histórico-Cultural e Polo Teresina (BRASIL, 2018).

${ }^{3} \mathrm{http}: / /$ www.barragrandepiaui.com/

\section{Referências}

ARAÚJO, G. P.; GELBCKE, D. L. Turismo Comunitário: Uma perspectiva ética e educativa de desenvolvimento. Revista Turismo Visão e Ação, Balneário Camboriú, v. 10, n. 3, p. 357-378, 2008.

BARBIERI, J. C.; SILVA, D., da. Desenvolvimento sustentável e educação ambiental: uma trajetória comum com muitos desafios. Revista de Administração Mackenzie (Mackenzie Management Review), v. 12, n. 3, 2011.

BARRETO, M. Manual de iniciação ao estudo do turismo. São Paulo: Papirus, 2006.

BENI, M. Como Certificar o Turismo Sustentável?. Turismo em Análise, São Paulo, v. 14, n. 2, p. 5-16, 2003. 
BRASIL. Ministério do Turismo. Segmentação do Turismo e o Mercado. Brasília: 1 ed., 2010.

BRASIL. Ministério do Meio Ambiente. Resolução CONAMA n. 357, de 17 de março de 2005. Dispõe sobre a classificação dos corpos de água e diretrizes ambientais para o seu enquadramento, bem como estabelece as condições e padrões de lançamento de efluentes, e dá outras providências. Diário Oficial da República federativa do Brasil, Brasília, Seção 1, p. 58-63. 2005.

BRASIL. Ministério do Meio Ambiente. PNRS - Política Nacional de Resíduos Sólidos. (2010). Lei oㅡ 12.305/2010. Institui a Política Nacional de Resíduos Sólidos e dá outras providências. Disponível em $<$ http://www.planalto.gov.br/ccivil 03/ ato2007-2010/2010/lei/l12305.htm>.

Acesso em 15 jan. de 2019.

CARVALHO, S. M. A percepção do turismo por parte da comunidade local e dos turistas no município de Cajueiro da Praia-PI. Revista Turismo em Análise, v. 21, n. 3, p. 470-493, 2010.

CMMAD - Comissão Mundial sobre Meio Ambiente e Desenvolvimento. Nosso futuro comum. Fundação Getúlio Vargas, Rio de Janeiro, 1998.

COSTA, A. S. Turismo e desenvolvimento local sustentável em Barra Grande - Cajueiro da Praia/PI. 105f. Dissertação (Mestrado em Desenvolvimento e Meio Ambiente) - Universidade Federal do Piauí (UFPI). Teresina, 2006.

CUNHA, J. M. A. da; SILVA, M. V. da. O turismo global em Barra Grande (PI): novos processos socioculturais, multifuncionalidade e pluriatividade no espaço rural. Capa, v. 11, n. 2, 2018.

CUNHA, J. M. A. da et al. Turismo (in) sustentável em Barra Grande (PI): conflitos, impactos, desigualdade e exclusão social. Revista Geografar, v. 11, n. 1, p. 152-173, 2016.

(DGA) Direcção Geral do Ambiente. Proposta para um sistema de indicadores de desenvolvimento sustentável. 2000. Disponível em $<$ http://www.iambiente.pt/sids/sids.pdf $>$. Acesso em 15 de jan. de 2015.

DUARTE, L. R. R. Os fundamentos e o fortalecimento do turismo comunitário a partir da Rede Tucum-CE. Revista Gestão \& Desenvolvimento, v. 1, n. 1, 2013.

FONSECA, J. J. S. Metodologia da pesquisa científica. Fortaleza: UEC, 2002. Apostila.

FREITAS, S. T. et al. Conhecimento tradicional das marisqueiras de Barra Grande, área de proteção ambiental do delta do Rio Parnaíba, Piauí, Brasil. Ambiente \& Sociedade, v. 15, n. 2, p. 91-112, 2012.

GIL, A. C. Como elaborar projetos de pesquisa. 4. ed. São Paulo: Atlas, 2007.

GODOY, L. H. et. al. Potencial Geoparque de Uberaba (MG): geodiversidade e geoconservação. Revista Sociedade e Natureza, v. 1, p. 395-410, 2013. 
GOLDENBERG, M. A arte de pesquisar. Rio de Janeiro: Record, 1997.

GUZZY, A (Org). Biodiversidade do Delta do Parnaíba: litoral piauiense. Parnaíba: EDUFPI, 2012.

HANAI, F. Y. Sistemas de Indicadores de Sustentabilidade: uma aplicação ao contexto de desenvolvimento do turismo na região de Bueno Brandão, estado de Minas Gerais, Brasil. 2009. f. Tese (Doutorado em Ciências da Engenharia Ambiental) - Universidade de São Paulo (USP). São Carlos, 2009.

ICMBIO - INSTITUTO CHICO MENDES DE CONSERVAÇÃO DA BIODIVERSIDADE. Unidades de Conservação. Brasília, 2012.

INSTITUTO BRASILEIRO DE GEOGRAFIA E ESTATÍSTICA. Indicadores de desenvolvimento sustentável: Brasil. 2012. Disponível em $<\mathrm{ftp}: / /$ geoftp.ibge.gov.br/documentos/recursos naturais/indicadores desenvo Ivimento sustentavel/2012/ids2012.pdf>. Acesso em 15 de out. de 2013.

INSTITUTO BRASILEIRO DE GEOGRAFIA E ESTATÍSTICA. Municípios@IBGE. 2018. Disponível em: <https://cidades.ibge.gov.br/ brasil/pi/cajueiro-da-praia/panorama>. Acesso em 17 de jan. de 2018.

IPEA - Instituto de Pesquisa Econômica Aplicada (2014). Lixo: País não conseguiu erradicar os lixões no prazo; coleta avançou. Acessado em 10 setembro, 2018, de http://www.ipea.gov.br/agencia

IPIRANGA, A. S. R.; GODOY, A. S.; BRUNSTEIN, J. Introdução. RAM, Rev. Adm. Mackenzie (Online), São Paulo, v. 12, n. 3, p. 13-20, junho de 2011.

MACÊDO, E. M.; RAMOS, R. G. O desenvolvimento do turismo em Barra Grande, Piauí (Brasil) e seu significado para a comunidade local. RITURRevista Iberoamericana de Turismo, v. 2, n. 2, p. 89-107, 2012.

MALHEIROS, T. F.; PHLIPPI JR, A.; COUTINHO, S. M. V. Agenda 21 nacional e indicadores de desenvolvimento sustentável: contexto brasileiro. Saúde e Sociedade, v. 17, p. 7-20, 2008.

MAY, P. H. Economia do meio ambiente: teoria e prática. Ed. $3^{\circ}$, Elsevier Brasil: Rio de Janeiro, 2018.

MENDONÇA, T. C. M. de; MORAES, E. A. de. Turismo de Base Comunitária sob influência do processo de Proteção da Natureza na Reserva Extrativista Prainha do Canto Verde (CE) e na Reserva de Desenvolvimento Sustentável do Aventureiro (RJ). Revista Capa, n. 9, v. 1, 2016.

MERICO, L. F. K. Políticas Públicas para a sustentabilidade. In: VIANA, G.; SILVA, M.; DINIZ, N. (Org.). O desafio da sustentabilidade: um debate socioambiental no Brasil. Editora Fundação Perseu Abramo, São Paulo: p. 251-262, 2011.

MIELKE, E. J. C. Desenvolvimento turístico de base comunitária: uma abordagem prática e sustentável. Editora Alínea, São Paulo. 2009.

MINAYO, M. C. S. (Org.). Pesquisa social: teoria, método e criatividade. Petrópolis: Vozes, 2001. 
OLIVEIRA, V. M. DE; GÓMEZ, C. P.; CÂNDIDO, G. A. Indicadores de sustentabilidad para la actividad turística: Una propuesta de monitoreo usando criterios de análisis. Estudios y Perspectivas en Turismo, v. 22, p. 177-197, 2013.

ORGANIZAÇÃO MUNDIAL DO TURISMO. Indicadores de desarrollo sostenible para los destinos turísticos: guía práctica. OMT, Madrid, 2005.

SACHS, I. De volta à mão visível: os desafios da Segunda Cúpula da Terra no Rio de Janeiro. Estudos Avançados, v. 26, n. 74, p. 5-20, 2012.

SAMPAIO, C. A. C.; ZAMIGNAN, G. Estudo da demanda turística: experiência de turismo comunitário da microbacia do Rio Sagrado, Morretes (PR). Cultur-Revista de Cultura e Turismo, v. 6, n. 1, p. 25-39, 2015.

SAMPAIO, C. A. C; CORIOLANO, L. N. Dialogando com experiências vivenciadas em Marraquech e América Latina para compreensão do Turismo Comunitário e Solidário. Revista Brasileira de Pesquisa em Turismo, v. 3, n. 1, 2009.

SANTOS, J. G. Sistema de Indicadores de Sustentabilidade para o Turismo: aplicação de uma abordagem participativa em Porto de Galinhas, PE. 2013. 160f. Dissertação (Mestrado em Administração (UFPE). Pernambuco, PE.

SILVA, G. V. da. et al. Contribuições da Educação Ambiental para o turismo em Bragança (PA) (Amazônia Atlântica): uma perspectiva participativa. Revista Capa, v. 6, n. 3, 2013.

SILVA, D. R. da. et al. Turismo Comunitario en Favelas: Un estudio del favela in Hostel, Chapéu Mangueira - Rio de Janeiro, Brasil. Estudios y perspectivas en Turismo, v. 23, p. 786-804, 2014.

SILVA, M. L. da et al. The image of the tourist destination as a differentiation tool and tourism promotion: if Barra Grande/PI-Brazil. PASOS: Revista de Turismo y Patrimonio Cultural, v. 14, n. 2, p. 417-431, 2016.

SOARES, É. B. Silva; EMMENDOERFER, M. L.; MONTEIRO, L. P. Gestão pública no turismo e o desenvolvimento de destinos turísticos em um estado da Federação Brasileira: uma análise do planejamento estratégico do turismo em Minas Gerais (2007-2010). Tourism \& Management Studies, v. 9, n. 2, p. 50-56, 2013.

SOUSA MELO, R. de; MONTEIRO, M. do S. L.; BRITO, A. S. Desenvolvimento Turístico e Sustentabilidade na Unidade de Conservação APA do Delta do Parnaíba (PI). Capa, v. 11, n. 3, 2018.

SOUZA, J. R. de et al. A importância da qualidade da água e os seus múltiplos usos: caso Rio Almada, sul da Bahia, Brasil. REDE-Revista Eletrônica do Prodema, v. 8, n. 01, 2014.

SPERB, M. P.; TELLES, D. H. Q. Gestão de Resíduos Sólidos e Turismo: O Tratamento Dado por Meios de Hospedagem e Pelo Setor Público na llha do Mel, PR. ROSA DOS VENTOS-Turismo e Hospitalidade, v. 6, n. 4, 2015.

SWARBROOKE, J. Turismo sustentável: conceitos e impacto ambiental. Aleph, 1, 2000. 
TRENTIN, F.; SANSOLO, D. G. Políticas públicas de turismo e indicadores de sustentabilidade ambiental: um estudo sobre Bonito - MS. Turismo Visão e Ação, v. 8, n. 1, p. 61-74, 2006.

TRIVIÑOS, A. N. S. Introdução à pesquisa em ciências sociais: a pesquisa qualitativa em educação. São Paulo: Atlas, 1987.

VIEIRA, A. F.; ARAÚJO, J. L. L. Turismo e sustentabilidade ambiental na comunidade de Barra Grande, Cajueiro da Praia, Piauí (PI). Revista Brasileira de Pesquisa em Turismo, v. 9, n. 3, p. 519-536, 2015.

Anderson Fontenele Vieira: Universidade Federal do Piauí, Parnaíba, PI, Brasil.

E-mail: anderson_ufpi@hotmail.com

Link para o currículo Lattes: http://lattes.cnpq.br/0233111583546130

Wilza Gomes Reis Lopes: Universidade Federal do Piauí, Teresina, PI, Brasil.

E-mail: wilzalopes@hotmail.com

Link para o currículo Lattes: http://lattes.cnpq.br/2455108901174407

José Luis Lopes Araújo: Universidade Federal do Piauí, Teresina, PI, Brasil. E-mail: jlla@ufpi.edu.br

Link para o currículo Lattes: http://lattes.cnpq.br/7066670272238569

Data de submissão: 21 de janeiro de 2019

Data de recebimento de correções: 16 de abril de 2019

Data do aceite: 16 de abril de 2019

Avaliado anonimamente 